\title{
A Concept Map for Design Method Experiments in Product Development - A Guideline for Method Developers
}

Selin Üreten ${ }^{1}$, Matthias Eisenmann², Thomas Nelius², Shi Cao ${ }^{3}$, Sven Matthiesen ${ }^{2}$, Dieter Krause ${ }^{1}$

${ }^{1}$ Institute of Product Development and Mechanical Engineering Design (PKT), Hamburg University of Technology (TUHH), Germany

2 Institute of Product Engineering (IPEK),

Karlsruhe Institute of Technology (KIT), Germany

3 Department of Systems Design Engineering,

University of Waterloo, Canada

\section{Abstract}

Due to the emergence of experiments in product development and yet still missing systematic adjustment of the generic experimental design procedure to test design methods, a facilitation is required. A concept map to depict the most important elements to consider when validating design methods in an experiment was developed systematically to guide method developers. Combining literature findings with the analysis of six cases in academia and an intensive exchange of researchers between different institutions resulted in the concept map. Future research potentials in the definition of variables, gaining objective results and managing the required tools are outlined. The concept map is available online for further feedback from the community.

Keywords: Method Validation, Experimental Design, Concept Map, Design Method Research 


\section{Research Motivation and Goal}

Experiments are widely used in different areas of science to gain reliable results. The areas are diverse [1], ranging from psychology over educational sciences to engineering design. Experiments have also become more popular over the years in product development and design research [2] especially with regards to the testing of approaches and methodologies.

Experiments provide a powerful study design to establish causal relationships between variables $[1,3]$. This study design can also be helpful in testing and validating design methods concerning certain criteria for the validation of methods. To gain replicable results about design methods, experiments need to be prepared, conducted and evaluated systematically. However, there are no guidelines or the like about what the main concepts are to consider for an experimental study design in product development, in specific, for the testing and validation of design methods. Examples for design methods are problem solving or modularization methods [4].

The goal of this paper is to present a facilitation to researchers in planning, conducting, analysing and reporting experiments with human participants to test and validate new developed methods in product development. The target group consists of researchers with engineering or design background, who have no or little experience in conducting experiments. This work especially addresses method developers in academia and can be helpful to other groups in industry with interest in validation of design methods, too.

This facilitation thus requires to derive the key elements of an experimental study design and adjust the generic experimental design procedure with specifications to testing design methods in order to support method designers' work. In specific, the facilitation should give an overview by making existing relations between different concepts clear, structure the knowledge and narrow it down to the most important key information necessary to start the experiment design. Besides creating awareness for the most relevant concepts, the visualisation should be appealing, enhance a common understanding and foster communication between the stakeholders.

According to Nückles et al. [5], mapping tools help to structure and reduce the topic treated to the most important aspects, visualise the contents, communicate knowledge and facilitate a mutual understanding. This common understanding can foster the elaboration of the map and fill it with in-depth experiences and knowledge through an exchange. New ideas are stimulated through the creative process of developing the map. Especially concept maps 
help to visualise the relations between the concepts identified. [5] Thus, a concept map has been chosen as a documentation format to support the method researchers in gaining a quick start to designing their own method experiment. This contribution can be seen as a kickoff for discussion about and feedback on the concept map for its further optimisation.

\section{Methodical Approach for Developing the Concept Map}

Experts in three different academical institutions collaborated for the concept map's development. The expertise comes from the areas of product development, human factors as well as experimental design and ranks from $\mathrm{PhD}$ students and researchers up to professors. As a basis for the concept map, a collection of contents is needed to link them within the map. Section 2.1 describes how those contents were collected and relates the collection to an overall development process. For the detailed development of the concept map, the authors followed a procedure suggested by Nückles et al. [5] as described in section 2.2.

\subsection{Collaborative Development Process}

The contents of the developed concept map are built upon two fundamental streams. First, experimental-methodical basics taken from literature and second, design method-specific intricacies for testing methods in product development from the academic institutes, see Figure 1. The experimental-methodical steps originate from literature in the field of psychology with focus on experimental design.

Regarding the methodical-organisational approach to develop the concept map, one can say that the initial concept map is based on literature findings, see Figure 1 . It is enriched by design method-specific content by analysing three experiments conducted in one scientific institution. This enriched concept map has then been extended through feedback of two other institutions of which one nurtured the map with three more cases involving method experiments. Further scientific exchange between the three institutions authoring this contribution enabled the optimisation of the map with regards to content as well as visualisation. The developed concept map is presented in section 4. 


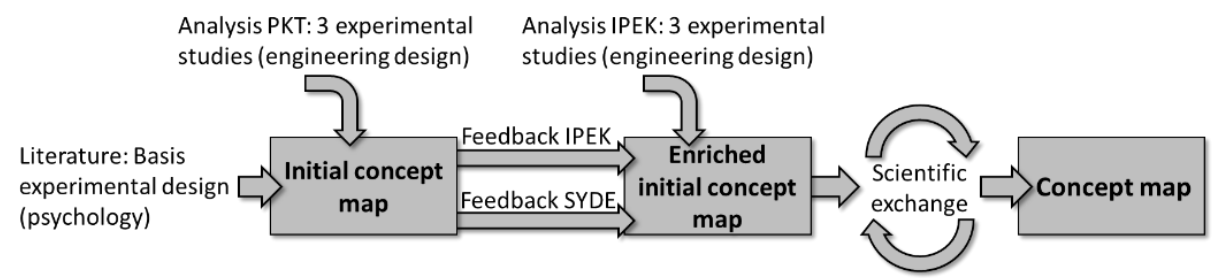

PKT - Institute for Product Development and Mechanical Engineering Design, Hamburg University of Technology IPEK - Institute of Product Engineering, Karlsruhe Institute of Technology

SYDE - Systems Design Engineering, University of Waterloo

Figure 1: Procedure for Developing and Enriching the Concept Map

The concept map was digitalised with Powerpoint. It has been published online (see link section 4) to allow access to other stakeholders and feedback for its further development is welcome.

\subsection{Detailled Procedure to Develop the Concept Map}

In each step described in section 2.1. the authors used a procedure proposed by Nückles et al. [5]. This procedure consists of nine steps and is summarised as follows. It starts with the choice of a focus topic for the concept map. Our concept map is built upon the focus question "Which elements should be considered in an experimental study design to test design methods in product development?" Important keywords regarding the focus topic have to be listed and the most inclusive keyword is taken and encircled (=knot). Keywords originated from experimental design literature in psychology. The three own cases' analyses filled that list further. This concept maps' most inclusive term is "Design method analysis experiment" and it is put in a rectangle. While adding more terms with knots from the list to the map, it should always be considered how the terms relate to each other. This is not only important for the adding and labeling of connections between related concepts, but also for an enhanced structure to get an overview. We have attempted for a chronological order from top to bottom with detailing to the left and right of the main procedural flow. This procedure is repeated until all elements from the list are included in the map. At the end, Nückles et al. [5] recommend to check the developed map for clear labeling, (alternative) strucutures, different perspectives and gaps for instance. The map has been checked for all above mentioned aspects by the individual research teams within the institutions as well as in an institution-wide exchange. An international scientific exchange comprising different perspectives on the topic took place. Elements with the same colour indicate a strong relationship among them and a common topic. Examples are 
given in fader rectangles. In future representations, it can be thought of enabling clicking on the rectangular elements and displaying of the related terms or examples. One crucial contribution from engineering design and adaption to experiments in psychology are the blue concepts (see section 4).

\section{Development of the Concept Map}

This section outlines the contents, which have been implemented in the developed concept map. The literature findings in the field of psychology for the design of experiments will be presented in section 3.1. The field of psychology is chosen as experiments are an already established research method in psychology and thus can provide a useful basis. The fundamental elements explained in this field of literature will be extended through and specified by cases in the field of product development experiments conducted in the research institutes authoring this contribution in section 3.2.

\subsection{Experimental-Methodical Basics from Psychology}

Experimental design is categorised into the quantitative research methods in the field of psychology, which is allocated to empirical sciences [6]. Thus, findings for both empirical study designs and experiments in psychology and social sciences have been used as a basis. There is a range of literature about experimental design in psychology. The fundamentals and most important concepts for experimental design in psychology have been aggregated and summarised in Table 1 with regards to the needs in this contribution. They are based on Hussy et al., Robson and Field and Hole $[6,7,8]$.

Table 1: Summary of Key Elements for Experiments [6-8]

\section{Experimental Design Elements}

- Formulation of reseach topic, question, -Types (in-field, laboratory, true and hypotheses

-Definition of variables (independent and dependent) quasi-experiment)

- Experiment plan (testing procedure, conditions, number of tests etc.)

- Disturbing variable, constant conditions

- Operationalisation of variables

- Sample

- Grouping of participants

- Conditions (control and experiment, within-subject design, in-between subject design)

- Causality

- Data collection

- Data analysis

- Error, bias, threats to validity

- Ethical considerations (informed consent, debriefing and confidentiality)

- Reliability, objectivity and validity (internal, external and construct validity)

- Documentation, reporting 


\subsection{Design Method-Specific Cases - Studies from PKT and IPEK}

As a next step, specific adaptions and extensions to the concept map were made through considering findings of six own experimental studies. These experiments originate from PKT and IPEK - three cases of each institute. Own cases have been used, as we know the details of how the studies were conducted and adjusted to our method-specific needs in product development. The own cases bring the advantage to trace back systematically and document them transparently. One experiment's analysis will be used and presented in detail to explain the general procedure of how the experiences and insights were transferred into the concept map. In the following description, identified concepts are printed in italic to illustrate the findings related to method experiments.

The first analysed case refers to an experiment conducted by PKT for a validation of a methodical adaption in a single method step in the life phases modularization method. This design method is part of the integrated PKT-approach [4] for developing modular product families. The step of modularization should be facilitated and the method's acceptance should increase by using an additional support material. The independent variable was the method aid given to the engineering design students during the experiment and the dependent variable was the group's performance. The operationalised variables were measured through self-assessment of the students and enriched by feedback from tutors and observers' real-time observations, which were documented in protocols. Whilst two conditions are included in a publication [9], many more levels have been developed for this experiment.

The following learnings from this case have been included in the concept map: study goal can be a method adaption with focus on method acceptance, measuring the variables may require different research tools such as surveys or focus groups and various technologies such as audio recorders. The design of a good task for an experimental environment is added and engineering design students as participants are included. The issue of bias has come up and includes that the research team needs to be trained accordingly. The most important keywords are added in a list and aligned in the concept map and linked with other concepts in accordance with the procedure explained in 2.1. The remaining cases will be presented in a nutshell with their key facts in Table 2 . Findings can be overlapping. The cases were analysed according to already existing concepts in the map and design method-specific criteria such as the before presented "method acceptance". These findings were added to the concept map with respective orientation to have a structured overview. Relations 
are added and reflected. These two latter steps are repeated iteratively (see 2.2) until no new information was found in the analysed case.

\section{Table 2: Summary of Experimental Cases Analysed to Extend the Concept Map}

\begin{tabular}{|c|c|}
\hline $\begin{array}{l}\text { Case Nr. - Goal; Tested } \\
\text { Method [Source] }\end{array}$ & Main Learnings/Added elements \\
\hline $\begin{array}{l}\text { 1- Validation of a methodical } \\
\text { adaption in a single method } \\
\text { step; adapted life phases modu- } \\
\text { larization - method aid [9] }\end{array}$ & $\begin{array}{l}\text {-Study Goal: method adaption, single method step } \\
\text {-Focus: method acceptance } \\
\text {-Experiment Design: task } \\
\text {-Participants: engineering design students } \\
\text {-Bias } \\
\text {-Research Tools: surveys, focus groups } \\
\text {-Technology: audio recorders } \\
\text {-Training research team }\end{array}$ \\
\hline $\begin{array}{l}\text { 2- Validating the order of using } \\
\text { different approaches to solve a } \\
\text { problem; the procedure to use } \\
\text { design catalogues by Roth [10] } \\
\text { [11] }\end{array}$ & $\begin{array}{l}\text {-Study Goal: method adaption, single method step } \\
\text {-Focus: method acceptance } \\
\text {-Participants: background and prior knowledge of students, stu- } \\
\text { dents as participants } \\
\text {-Data Collection: qualitative and quantitative feedback } \\
\text {-Research Tools: repeated surveys, oral feedback }\end{array}$ \\
\hline $\begin{array}{l}\text { 3- Initial validation of a docu- } \\
\text { mentation tool for a method } \\
\text { step; adapted life phases modu- } \\
\text { larization }\end{array}$ & 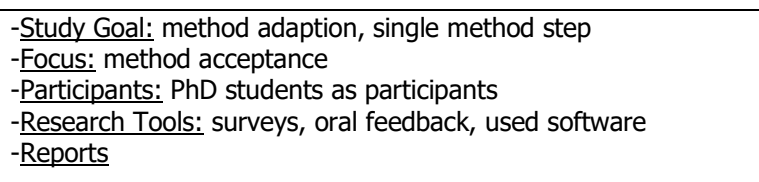 \\
\hline $\begin{array}{l}\text { 4-Evaluating a debiasing method } \\
\text { for analysis in engineering de- } \\
\text { sign; simplified version of Analy- } \\
\text { sis of Competing Hypothesis } \\
\text { (ACH) }[12],[13]\end{array}$ & $\begin{array}{l}\text { - Bias } \\
\text { - Research Tool: observation, think-aloud, survey } \\
\text { - Technology: eye tracking, video } \\
\text { - Participants: students, design engineers } \\
\text { - Focus: validating a modified and transferred method } \\
\text { - Dimension of validation: usefulness } \\
\text { - Data analysis: statistical }\end{array}$ \\
\hline $\begin{array}{l}\text { 5- Improving decision making by } \\
\text { teaching debiasing approaches; } \\
\text { reflection as a method for prod- } \\
\text { uct developmet in order to } \\
\text { a) improve motivation } \\
\text { b) improve performance [14] }\end{array}$ & $\begin{array}{l}\text { - Experimental design: between-subject } \\
\text { - Participants: engineering students in the same semester } \\
\text { - Variables: operationalisation of BOTH independent and de- } \\
\text { pendent variable necessary } \\
\text { - Focus: transferring a method from another field to engineering } \\
\text { - Dimension of validation: usefulness, multiple dependent varia- } \\
\text { bles } \rightarrow \text { usefulness has many aspects }\end{array}$ \\
\hline $\begin{array}{l}\text { 6- Validating modelling of em- } \\
\text { bodiment function relations as a } \\
\text { single aspect of C\&C2-Approach; } \\
\text { modelling of embodiment funci- } \\
\text { ton relations (EFR) } \\
\text { Indep. Variable: development } \\
\text { success [15] }\end{array}$ & $\begin{array}{l}\text {-Experimental design: quasi-experiment } \rightarrow \text { control- } \& \text { experi- } \\
\text { mental group get separated by their value of independent varia- } \\
\text { ble, duration of experiment } \rightarrow 1 \text { whole semester ( } 4 \text { months) } \\
\text { - Focus: validation of a single aspect of a design method } \\
\text {-Operationalisation: should produce a measurable variable, that } \\
\text { is reliable but doesn't lose its construct validity } \\
\text {-Technology: accompanying online survey during semester }\end{array}$ \\
\hline
\end{tabular}




\section{The Developed Concept Map}

The presented concept map is a simplified and reduced map for a facilitated understanding in this contribution, see Figure 2 . Details to it can be found online: https://www.researchgate.net/publication/335070232_A_Concept_Map_for_Design_Method_Experiments_in_Product_Development_-_A_Guideline_for_Method_Developers.

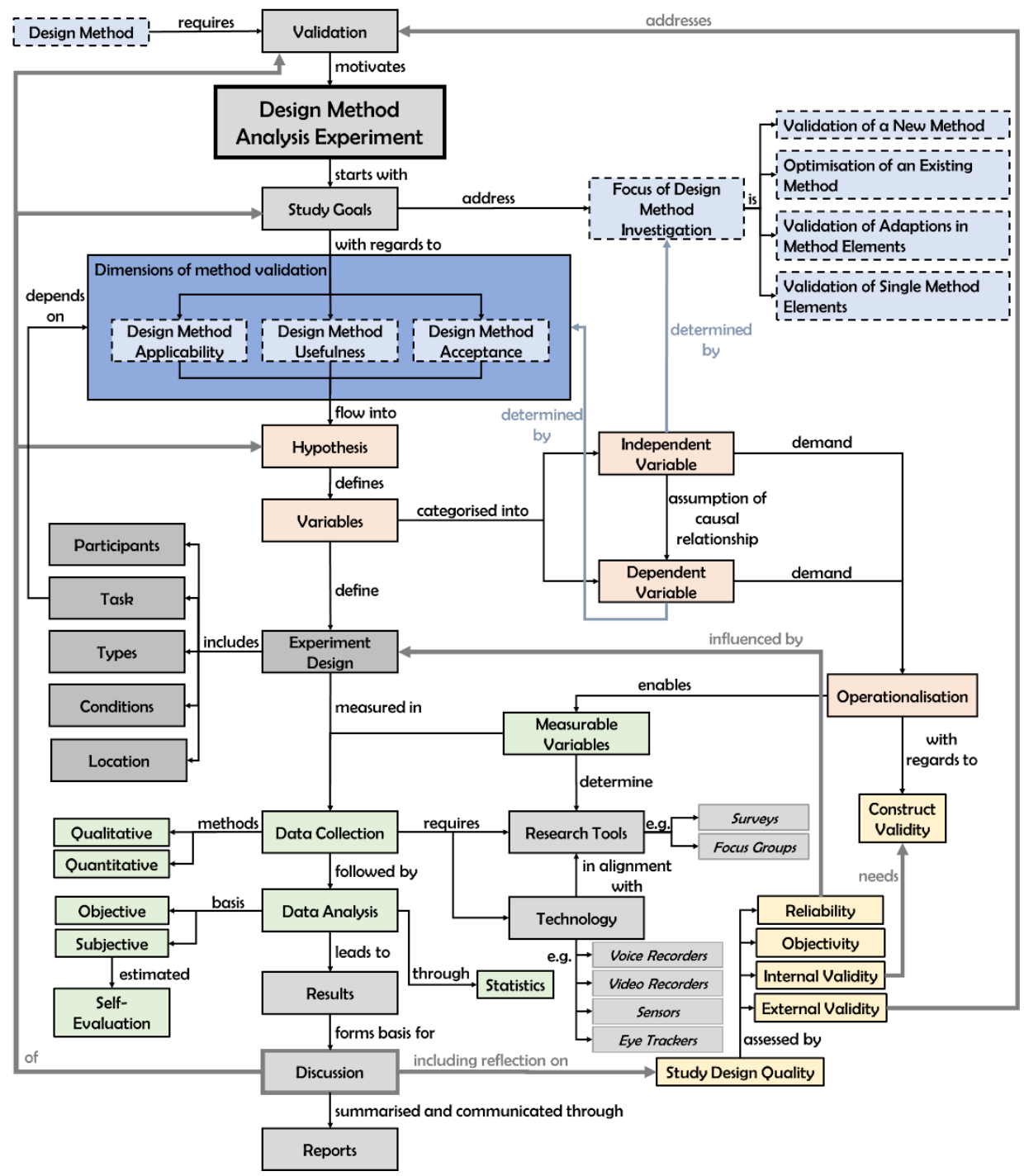

Figure 2: Simplified Concept Map 
In general, the following characteristics of the concept map are significant: The map includes general concepts from experiments in psychology and social sciences, such as the building of "Hypothesis" and definition of "Variables" and design method-specific adaptions. One adaption is the basis for "Hypothesis" resulting from the validation dimensions "Design Method Applicability", "Usefulness" or "Acceptance". The main adaptions for testing design methods with experiments are given in blue colour and dashed lines. A colour code is used to point out strongly related concepts to a specific topic. Several main concepts are defined with examples in the concept map, which are written in italic and in grey rectangular boxes. The "Focus of Design Method Investigation" can be categorised into "Validation of a New Method", "Optimisation of an Existing Method", "Validation of Adaptions in Method Elements" and the "Validation of Single Method Elements". Another example for detailed concepts is "Technology" used during data collection, which is further detailed by examples of "Voice recorders", "Video recorders", "Eye trackers" and "Sensors". Though the concept map shows a general flow, it does not necessarily provide a 1-1 sequence of what to do next and how to do it in detail. Feedback loops exist inbetween the concepts: The "Variables"are linked to former concepts. The "Independent Variable"results from the "Focus of Design Method Investigation"and the "Dependent Variable" is given by one or a combination of the validation dimension(s). "Internal Validity" is related to "Construct Validity" given by an adequate "Operationalisation". Thick arrows symbolise a feedback to former aspects. It should be noted that the concept map was developed for having one independent variable only to keep it simple and enhance the method developers understanding of the general concepts. For multiple independent variables, the procedure can be adjusted and recommendations on how to work with multiple independent variables and the results can be specified. The map has a focus on the expertise of each author and this is the basis for emphasis. There are many more relations between the concepts but only the most important ones according to the authors were chosen.

\section{Discussion}

This section demonstrates the strengths and limitations of the developed concept map with a presentation of its future potential for further research. A major strength of this contribution is that three different institutions have contributed to the successful development of the concept map with in total six analysed cases and complementary expertise. These cases differ in the applied methods (e.g. life phases modularization, working with engineering design catalogues, debiasing), their data collection techniques and tools (e.g. eye tracking, study observers), and the type of work (e.g. method for indivudal application, team-based method). This covers a broad range of adaptions of 
the experimental design procedure from psychology to testing design methods. The scientific exchange and various feedback loops between PKT in Hamburg, IPEK in Karlsruhe, both situated in Germany and the Systems Design Department in Waterloo, Canada, have helped to extend the expertise, gain different perspectives, confirm aspects, add new elements and detail the concept map. Additionally, optimisations in the visualisation could also be possible thanks to this exchange. Various researchers within the institutions and students have tested the concept map and their feedback was incorporated, too. Limitations refer to a more general level of developing the contents of the concept map such as to the more specific details of filling and adapting the concept map in the future. The current version gives an overview and is intended to give an inspiration for further own studies on learning the individual concepts by the method developer. These limitations lead to following future research potentials:

1. Detailing individual concepts. To give an example, the three dimensions applicability, usefulness and acceptance, and further concepts in design research, such as students' understanding of a technical system, can be be subject to future research with regards to finding latent constructs and operationalisation.

2. Operationalisation as key to validity. Design method experiments are still a new research tool in the field of engineering design. Further research should therefore focus on construct validity of the undertaken operationalisation, because it is the key for producing objective and valid results. Without fitting measurable variables, valid statements regarding the study goals are not possible.

3. Managing technology and expertise required to objectively measure data and thus complement self-evaluation of the participants. However, conducting experiments requires various resources. The goal is to maximise reliable output and results with minimal resources.

4. Considering usability criteria for the method developers using experiments. Research into how experiments can be designed and their planning facilitated, such that designers like to see and also use them.

\subsection{Publication of the Concept Map and Call for Feedback}

The concept map developed by the institute PKT, IPEK and SYDE has been made publicly available for the design community and further interested peo- 
ple. Feedback is highly welcome to keep the map up-to-date and further optimisation. We are looking forward to hearing your feedback either through the feedback form or direct contact with the authors of this contribution.

\subsection{Conclusion}

A concept map to depict the most important elements of design method experiments has been developed including for engineering design researchers developing methods, who have no or little experience in the design of experiments. The concept map merges core elements from experimental design with human participants in the area of psychology with design method-specific adaptions. The map has been developed through the expertise of three different institutions, which have analysed six experimental cases in product development and followed an intensive exchange about this concept map.

\section{Acknowledgements}

The authors thank all colleagues and students who have provided their valuable insights and feedback to the concept map and this contribution.

\section{Literature}

[1] Blessing, L. T.M.; Chakrabarti, A.: "DRM, a Design Research Methodology", Springer, Dordrecht, Heidelberg, London, New York, 2009.

[2] Cash, P.; Stanković, T.; Štorga, M.: "An Introduction to Experimental Design Research"; In: "Experimental Design Research. Approaches, Perspectives, Applications", Cash, P.; Stanković, T.; Štorga, M. (Eds.), Springer, Switzerland, 2016.

[3] Yin, R. K.: "Case Study Research and Applications. Design and Methods", 6th edition, Los Angeles, London, New Delhi, Washington DC, Melbourne, 2018.

[4] Krause, D.; Gebhardt, N.: "Methodische Entwicklung modularer Produktfamilien. Hohe Produktvielfalt beherrschbar entwickeln", Springer Vieweg, Berlin, Germany, 2018.

[5] Nückles, M.; Gurlitt, J.; Pabst, T.; Renkl, A.: "Mind Maps \& Concept Maps: Visualisieren, Organisieren, Kommunizieren", Deutscher Taschenbuch Verlag, Munich, 2004. 
[6] Hussy, W.: Schreier, M.; Echterhoff, G.: "Forschungsmethoden in Psychologie und Sozialwissenschaften". Springer, Berlin, Heidelberg, New York.

[7] Robson, C.: "Real World Research. A Resource for Users of Social Research Methods in Applied Settings". Third Edition. Wiley, United Kingdom, 2011.

[8] Field, A.; Hole, G.: "How to Design and Report Experiments", Sage, Los Angeles, London, New Delhi, Singapore, Washington DC, 2011.

[9] Üreten, S.; Beckmann, G.; Schwenke, E.; Krause, D.; Cao, S.: "Continuing Education and Personalization of Design Methods to Improve their Acceptance in Practice - An Explorative Study", Procedia CIRP, Volume 60, 2017, Pages 524-529, 27th CIRP Design Conference. DOI: 10.1016/j.procir.2017.01.012.

[10] Roth; K. (1994): Konstruieren mit Konstruktionskatalogen, Band II: "Konstruktionskataloge", 2nd edition, Springer, Berlin, Heidelberg, New York.

[11] Üreten, S.; Krause, D.: "Discursive vs. intuitive - An experimental study to facilitate the use of design catalogues", In: Proceedings of the 21st International Conference on Engineering Design (ICED17), Vol.9, Vancouver, Canada, 2017, pp. 99-108.

[12] Matthiesen, S.; Nelius, T.: "Managing Assumptions during Analysis - Study in successful Approaches of Design Engineers", In: Proceedings of NordDesign 2018, Sweden, 2018.

[13] Nelius, T.; Matthiesen, S.: "Experimental Evaluation of a Debiasing Method for Analysis in Engineering Design", in Proceedings of the 22nd International Conference on Engineering Design (ICED19), Delft, The Netherlands, 2019. DOI:10.1017/dsi.2019.53.

[14] Nelius, T; Eisenmann, M.; Doellken, M.; Hergl, M.; Matthiesen, S.: "Improving Decision Making by Teaching Debiasing Approaches - motivating Engineering Students with Reflection", In: Proceedings of the 2nd Human Behaviour in Design Conference (HBiD19), Germany, 2019.

[15] Grauberger, P.; Voß, K.; Matthiesen, S.: "Functional Analysis in Embodiment Design - An Investigation of Embodiment Function Relations in Testing Activities", In: Proceedings of the 22nd International Conference on Engineering Design (ICED19), Delft, The Netherlands, 2019. DOI:10.1017/dsi.2019.156. 